\title{
Immunohistochemical Expression of Cyclooxygenase-2 and Its Relationship With Prognostic Parameters in Breast Cancer
}

\author{
Leyla Tekin (1), Serkan Yașar Çelik (1) \\ Department of Pathology, Muğla Sıtkı Koc̣man University, School of Medicine, Muğla, Turkey
}

ORCID iDs of the authors: L.T. 0000-0003-II72-5536; S.Y.C̣. 0000-000I-6557-I45I.

\begin{abstract}
Cite this article as: Tekin L, Çelik SY. Immunohistochemical Expression of Cyclooxygenase-2 and Its Relationship With Prognostic Parameters in Breast Cancer. Cyprus J Med Sci 202I; 6(I): 39-43.

\section{BACKGROUND/AIMS}

Cyclooxygenase-2 (COX2) plays an important role in the development of some human cancers, especially in the development of pulmonary, colon, and breast carcinomas. Overexpression of COX2 has been involved in the pathogenesis of a wide range of malignancies, such as colon, breast, and lung cancer, and has been associated with carcinogenesis and tumor progression. The COX2 pathway has been involved in several processes associated with tumor progressions, such as angiogenesis, proliferation, and invasion. This study aimed to determine whether COX2 can be used as a prognostic marker in breast cancer.
\end{abstract}

\section{MATERIAL and METHODS}

We evaluated immunohistochemical expressions of COX2 in 100 patients with invasive ductal breast carcinoma and compared its utility as a prognostic parameter. In the evaluation of the data, chi-square test was used to assess the relationship between mean, standard deviation, and COX2 and the relationship between other independent variables in the Statistical Package for the Social Sciences version 24 software package.

\section{RESULTS}

A positive correlation was found between COX2 expression and estrogen receptor positivity, tumor grade, Ki67 proliferation index, tumor size, advanced age, and triple-negative subtypes $(P<.005)$. However, there was no association with HER2 positivity, progesterone receptor positivity, and nonluminal type.

\section{CONCLUSION}

In breast cancer, COX2 expression has a positive correlation with some prognostic parameters; however, it has an inverse correlation with some others.

Keywords: Breast cancer, COX2, immunohistochemistry

\section{INTRODUCTION}

Breast cancer is the most common malignancy in women, and its malignancy is one of the most common causes of death (I). Molecular characterization of this malignancy is an indicator for tumor prognosis and aggression. The classical molecular parameters of breast cancer are estrogen receptor (ER), progesterone receptor (PR), and cerbB2 expressions, and Ki67 proliferation index $(2,3)$.

Previous studies have shown that cyclooxygenase (COX)-2 plays an important role in the development of some human cancers, especially pulmonary, colon, and breast carcinomas, as well as preinvasive lesions. COX catalyzes the synthesis of prostaglandin endoperoxidase from arachidonic acid, which means that it is the first step in the biosynthesis of prostaglandins and thromboxane and is also known as prostaglandin endoperoxide synthase.

Of note, 2 prostaglandin synthase isoforms have been identified, which are often referred to as COXI and COX2 (4). AIthough COXI is structurally produced by most body tissues, COX2 is an inducible enzyme and is produced under certain conditions, such as inflammation and tumor microenvironment. COX2 plays a role in estrogen regulation by producing prostaglandin E2 that increases the expression of cytochrome P450 enzyme complex (also known as aromatase) that 
catalyzes estrogen production, which is mediated through androgen (5).

COX2 is the enzyme that regulates the inflammatory process and the first step of prostaglandin synthesis. Tissue expression of COX2 is regulated by cytokines, endotoxins, and growth factors (6). Overexpression of COX2 has been defined in the pathogenesis of a wide range of malignancies, such as colon, breast, and lung cancer, and has been associated with carcinogenesis and tumor progression, such as angiogenesis, proliferation, and invasion (7-9). COX2 plays a role in the induction of apoptosis (I0). High COX2 expression is more common in poorly differentiated tumors than in well-and moderately differentiated tumors. It has been shown that COX2 expression also correlates with poor prognostic factors, such as high $\mathrm{Ki}-67$ proliferative rate and low differentiation (I).

We aimed to evaluate COX2 expressions in invasive ductal breast cancer and adjacent benign breast tissue and to correlate them with clinical and histological prognostic parameters, including hormone receptor status.

\section{MATERIAL and METHODS}

This study was based on the retrospective analysis of tumors diagnosed as invasive breast carcinoma (without special type) from patients who underwent mastectomy between 2014 and 2019. A total of 100 patients were included in the study. A total of 4- $\mu \mathrm{m}$-thick sections were prepared from the paraffin block of tumors, and ER (clone: 6FII, I:50, Leica Biosystems, Thermo Fisher Scientific, IBM SPSS Corp, Germany), PR (clone: Pgrl6, I:I00, Leica Biosystems), Ki67 (clone: MMl optimized for use, Leica Biosystems), cerbB2 (clone: I0A7, I:40, Leica Biosystems), and COX2 (clone: SP2I, I:50, Thermo Fisher Scientific, Waltham, MA, USA) antibodies were applied by Leica Bond-Max brand fully automatic immunohistochemistry device. For each slide, hematoxylin was used as the counterstain. Immunohistochemical staining was evaluated with a light microscope (BX46 Clinical Microscope, Olympus, Tokyo, Japan). A minimum of 500 tumor cells was counted for the immunohistochemical evaluations per antibody.

Immunohistochemical staining percentages for ER and PR were made according to Allred's criteria, and the staining intensity of positive tumor cells was also categorized into 4 groups ( 0 , no staining; I, weak staining; 2 , medium staining; and 3, strong staining). CerbB2 receptor status was considered negative for 0 and I+ test results and positive for $3+$ test results; however, tumors with the $2+$ test results were retested by $\mathrm{FISH}$.

\section{Main Points:}

- It is important to monitor the progression of breast cancer, which is the most common type of cancer in women, and to direct the treatment. Therefore, the searches for various prognostic markers of this cancer continue.

- It is still early for COX2 to be an immunohistochemical prognostic marker for breast cancer because different results have been found in different studies.

- Further standardized studies may be needed before it can be considered a prognostic marker.
Medium to strong nuclear staining of $>1 \%$ of tumor cells for ER and $>20 \%$ of tumor cells for PR was considered positive. For Ki67, cases showing $>14 \%$ medium/strong nuclear tumor staining were considered positive. Cytoplasmic immunoreactivity of COX2 was graded according to the German Immuno Reactive Score (12). The staining intensity was graded from 0 to 3 ( $0=$ no staining, l=weak staining, $2=$ moderate staining, $3=$ strong staining). For statistical calculations, the COX2 status was evaluated by establishing 2 thresholds: positive and negative (negative and weak staining were grouped as negative, whereas medium and strong staining were grouped as positive [Figure I]).

\section{Breast Cancer Classification}

Breast cancer was classified as follows:

I. Luminal A: when estrogen/progesterone are positive, cerbB2 is negative, and Ki67 is low $(<14 \%)$.

2. Luminal $B$ negative, cerbB2 negative: when estrogen is positive, cerbB2 is negative, and ki67 is high ( $\geq 14 \%)$ and/or progesterone is positive $(<20 \%)$.

3. Luminal $B$ negative, cerbB2 positive: when estrogen is positive, cerbB2 is positive, there is any ki67 and any PR.

4. CerbB2 positive (nonluminal): when cerbB2 is positive, and estrogen/progesterone is negative.

5. Triple negative: estrogen/progesterone and cerbB2 are negative.

\section{Statistical Analysis}

In the evaluation of the data in this study, chi-square test was used for the assessment of the relationships between the mean, standard deviation, and COX2 and other independent variables by the Statistical Package for the Social Sciences 24 package program (IBM SPSS Corp;; Armonk, NY, USA). The relationships between COX2 and triple negative and those between COX2 and ER-positive, PR-positive, and cerbB2-positive cases were assessed. In the analyses, $\mathrm{P}<.05$ values were accepted as statistically significant.

\section{RESULTS}

The distribution of the surrogate subtypes of breast cancer in 100 samples was 56 (56\%) luminal A; 9 (9\%) luminal B, cerbB2

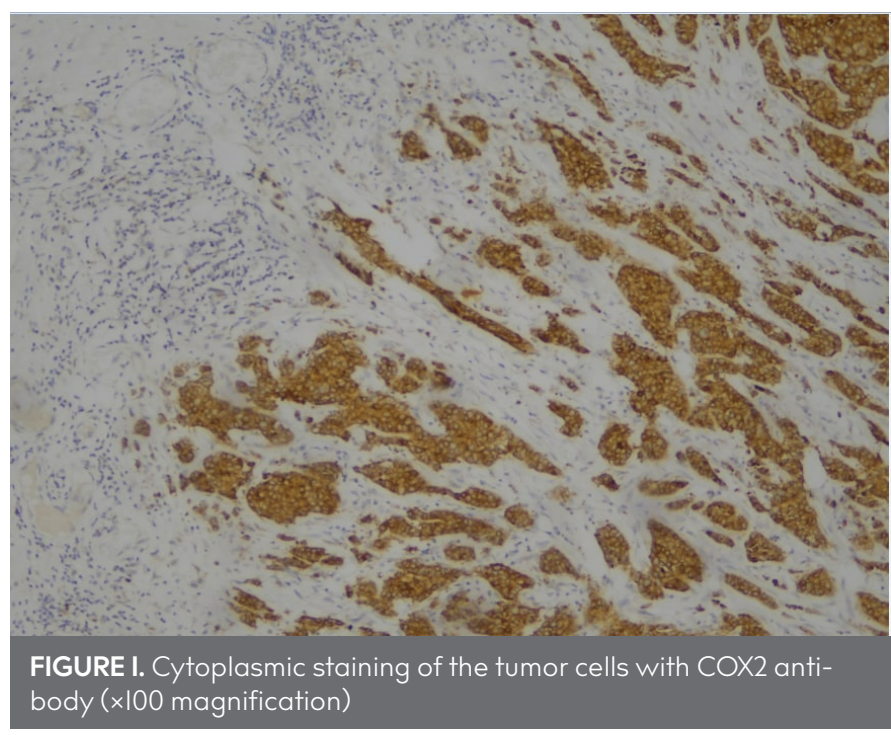




\begin{tabular}{|llcl|}
\hline TABLE I. The demographic characteristics of the cases & \\
\hline Demographic Parameters & & $\mathbf{n}(\mathbf{1 0 0})$ & $\%$ \\
\hline Tumor grade & Grade I & 20 & 20 \\
& Grade 2 & 62 & 62 \\
& Grade 3 & 18 & 18 \\
Tumor size & $2 \mathrm{~cm}<$ & 27 & 27 \\
& $2 \mathrm{~cm} \geq$ & 73 & 73 \\
Age & $30-48$ & 40 & 40 \\
& $49 \geq$ & 60 & 60 \\
Lymph node metastasis & $(+)$ & 34 & 34 \\
& $(-)$ & 66 & 66 \\
\hline
\end{tabular}

\begin{tabular}{|c|c|c|}
\hline Prognostic parameters & $\mathrm{COX} 2 \mathrm{X} \pm \mathrm{SD}$ & Level of significance \\
\hline Grade & $.66 \pm .76$ & \\
\hline Low (GI) & $.40 \pm .50$ & \\
\hline Medium (G2) & $.66 \pm .47$ & $X 2=0.01$ \\
\hline High (G3) & $.94 \pm .23$ & $p<0.05$ \\
\hline \multirow[t]{2}{*}{ ER+ } & $.77 \pm 42$ & $X 2=0.04$ \\
\hline & & $p<0.05$ \\
\hline \multirow[t]{2}{*}{ PR+ } & $.58 \pm .50$ & $X 2=0.094$ \\
\hline & & $p>0.05$ \\
\hline \multirow[t]{2}{*}{ cerbB2+ } & $.67 \pm .49$ & $X 2=0.095$ \\
\hline & & $p>0.05$ \\
\hline \multirow[t]{2}{*}{ Ki67(above 14\%) } & $.82 \pm .38$ & $X 2=0.09$ \\
\hline & & $p<0.05$ \\
\hline \multirow[t]{2}{*}{ Tumor size $>2 \mathrm{~cm}$} & $.80 \pm .40$ & $X 2=0.00$ \\
\hline & & $p<0.05$ \\
\hline \multirow[t]{2}{*}{ Age 49z } & $.81 \pm .39$ & $X 2=0.00$ \\
\hline & & $p<0.05$ \\
\hline \multirow[t]{2}{*}{ Lymph node metastasis $(+)$} & $.85 \pm .34$ & $X 2=0.01$ \\
\hline & & $p<0.05$ \\
\hline \multirow[t]{2}{*}{ Triple negativity } & $.94 \pm .25$ & $X 2=0.011$ \\
\hline & & $p<0.05$ \\
\hline
\end{tabular}

negative; 12 (12\%) luminal B, cerbB2 positive; 7 (7\%) cerbB2 positive (nonluminal); and 16 (16\%) triple negatives. The demographic characteristics of the cases are shown in Table I. For threshold definition, negative and poor staining results were grouped as negative, whereas medium and strong staining results were grouped as positive. When the statistical results were examined, the correlations between advanced/intermediate grades and COX2 expression $\left(\chi^{2}=0.01, P<.05\right)$ and that between ER positivity and COX2 expression ( $\left.\chi^{2}=0.004, P<.05\right)$ were statistically significant. It was determined that there was no statistical relationship between CerbB2 positivity and COX2 expression $\left(\chi^{2}=0.095, P>.05\right)$ and between PR positivity and COX2 expression $\left(\chi^{2}=0.094, P>.05\right)$. In addition, the relationships between $\mathrm{Ki} 67$ and COX2 expression $\left(\chi^{2}=0.09, \mathrm{P}<.05\right)$, between tumor size $>2 \mathrm{~cm}$ and COX2 expression $\left(\chi^{2}=0.00, P>.05\right)$, between age $>49$ years and $\operatorname{COX} 2$ expression $\left(\chi^{2}=0.00, P>.05\right)$, and between lymph node metastasis and COX2 expression $\left(\chi^{2}=0.01, P>.05\right)$ were found statistically significant. The relationship between COX2 expression and triple-negative subtype was found to be statistically significant $\left(\chi^{2}=0.00, P<.05\right)$ (Table 2).

Pathological parameters, such as peritumoral angiolymphatic invasion, perineural invasion, dermal invasion, in situ carcinoma component, luminal $A$, luminal $B$, and nonluminal subtypes were not associated with COX2 expression.

\section{DISCUSSION}

COX2 expression has been widely described in breast cancers. It shows high expression in tumor breast tissue compared with that in benign breast tissue and seems to have a clinical potential use in predicting the prognosis (I3). In an analysis of 12 studies, COX2 positivity was found in $42 \%$ of the tumors (14). In our study, $67 \%$ of tumors showed positivity for COX2. COX2 was found to be associated with increased tumor grade and poor prognosis among patients with estrogen-independent breast cancer because it is a main agent in the inflammation-cancer signal axis (15). Although COX2 expression was presented as a prognostic parameter in basal carcinomas, it showed no prognostic significance in luminal A cancers (16). However, Serra et al. (17) declared that COX2 expression was not related to clinical and pathological subtypes, tumor characteristics, and prognosis. COX2 positivity was found in the invasive and in situ carcinomas and also around the tumor $(14,17,18)$.

In a retrospective study of 303 high-grade breast cancers, COX2 was evaluated immunohistochemically, and a positive correlation was observed between COX2 overexpression and high tumor grade; however, no correlation was found with ER positivity (I5).

There are some other studies that found a reverse correlation between ER and COX2 expressions (19), and some others showed a positive correlation (20) such as in our study. Ristimaki et al. (20) suggested that elevated COX2 expression in ER-positive cancers could be because of the enhancement of the microenvironment for cancer cells to grow by inducing estrogen production. In addition, some studies have found a strong association of COX2 overexpression with ER negativity and the worse prognosis (2I).

Triple-negative breast cancers do not have ER, PR, and HER2 expressions, and they constitute 15\% of all breast cancers and are associated with aggressive progress, high metastasis, and poor prognosis (22). It has been reported that COX2 expression is increased in triple-negative and HER2+ (nonluminal) tumors $(23,24)$. In our study, COX2 expression seemed to be increased in triple-negative tumors, but no statistically significant relationship was observed with the HER2+ group. There are variations in the literature regarding COX2 positivity and negativity; therefore, it is difficult to compare between studies. Different results may occur in different immunohistochemical analyses owing to different antibodies, nonstandardized staining methods and differentiation differences of the tumors, and the differences in COX2 expression analysis. 
A recent meta-analysis of 21 studies and 6739 patients with breast cancer showed that the presence of high COX2 levels predicted a larger tumor size and lymph node metastasis, similar to our finding (25). When Ki67 is highly expressed as a nuclear cell proliferation marker in breast cancer, it is associated with a poor prognosis (26). There are studies emphasizing that there is a correct relationship between the number of cells expressing Ki67 and proliferation (27) or that there are no significant statistical results with $\mathrm{Ki67}$ expression (28). In this study, a positive correlation was found between the high value of $\mathrm{Ki67}(>14 \%)$ and COX2 expression.

In carcinogenesis, inflammatory cytokines, growth factors, endotoxins, and oncogenes trigger the induction of COX2 and cause tumor progression by participating in COX2 tumor proliferation, invasion, angiogenesis, apoptosis resistance, and metastasis $(29,30)$. Therefore, it is associated with poor prognosis in patients with cancer (20).

We have found a correlation of COX2 expression with some of the prognostic parameters in breast cancer. However, it appears to be early for COX2 immunoexpression to be used daily as a prognostic marker in breast cancer. It may be a good prognostic marker if it gains support from further studies with large series.

Ethics Committee Approval: Ethics committee approval was received for this study from the ethics committee of Muğla Sıtkı Koçman University (Approval date:180170/No:149).

\section{Informed Consent: N/A}

Peer-review: Externally peer-reviewed.

Author contributions: Concept - L.T.; Design - L.T.; Supervision - S.Y.C.; Resource - L.T, S.Y.C.; Materials - L.T, S.Y.C.; Data Collection and/or Processing - L.T., S.Y.C..; Analysis and/or Interpretation - S.Y.C.; Literature Search - L.T.; Writing - L.T.; Critical Reviews - S.Y.C.

Conflict of Interest: Authors have no conflicts of interest to declare.

Financial Disclosure: The authors declared that this study has received no financial support.

\section{REFERENCES}

I. DeSantis CE, Ma J, Goding Saver A, Newman LA, Jemal A. Breast cancer statistics, 2017, racial disparity in mortality by state. CA Cancer J Clin 2017; 67(6): 439-48. [Crossref]

2. Pakkiri P, Lakhani S, Smart C. Current and future approach to the pathologist's assessment for targeted therapy in breast cancer. Pathology 2009; 4I(I): 89-99. [Crossref]

3. Ross J, Slodkowska E, Symmans W, Pusztai L, Ravdin PM, Hortobagyi GN. The HER-2 receptor and Breast cancer: Ten years of targeted anti-HER-2 therapy and personalized medicine. Oncologist 2009; 14(4): 320-68. [Crossref]

4. Williams C, DuBois R. Prostaglandin endoperoxide synthase: why two isoforms? Am J Physiol Gastrointest Liver Physiol 1996; 270: 393-400. [Crossref]

5. Diaz-Cruz E, Shapiro C, Brueggemeier R. Cyclooxygenase inhibitors suppress aromatase expression and activity in breast cancer cells. J Clin Endocrinol Metab 2005; 90(5): 2563-70. [Crossref]

6. Shao Y, Sun K, Xu W, Li XL, Shen H, Sun WH: Helicobacter pylori infection, gastrin and cyclooxygenase-2 in gastric carcinogenesis. World J Gastroenterol 20|4; 20(36): 12860-73. [Crossref]
7. Harris RE, Casto BC, Harris ZM: Cyclooxygenase-2 and the inflammogenesis of breast cancer. World J Clin Oncol 2014; 5(4): 677-92. [Crossref]

8. Misra S, Sharma K: COX-2 signaling and cancer: New players in old arena. Curr Drug Targets 2014; 15(3): 347-59. [Crossref]

9. Wang D, Dubois RN: Eicosanoids and cancer. Nat Rev Cancer 20I0; IO(3): I8I-93. [Crossref]

10. Yuan L, Jiang R, Yang Y, Ding S, Deng H: 1,25-Dihydroxy vitamin D3 inhibits growth of the breast cancer cell line MCF-7 and down-regulates cytochrome P450IBI through the COX2/PGE2 pathway. Oncol Rep 20I2; 28(6): 2131-7. [Crossref]

II. Gao S, Sun Y, Liu X, Zhang D, Yang X. EpCAM and COX-2 expression are positively correlated in human breast cancer. Mol Med Rep 2017; 15(6): 3755-60. [Crossref]

12. Specht E, Kaemmerer D, Sänger J, Wirtz RM, Schulz S, Lupp A. Comparison of immunoreactive score, HER2/neu score and $\mathrm{H}$ score for the immunohistochemical evaluation of somatostatin receptors in bronchopulmonary neuroendocrine neoplasms. Histopathology 2015; 67(3): 368-77. [Crossref]

13. Kumar BNP, Rajput S, Dey RK, Parekh A, Das S, Mazumdar A, et al Celecoxib alleviates tamoxifen- instigated angiogenic effects by ROS-dependent VEGF/VEGFR2 autocrine signaling. BMC Cancer 2013; 13: 273. [Crossref]

14. Glover JA, Hughes CM, Cantwell MM, Murray LJ. A systematic review to establish the frequency of cyclooxygenase-2 expression in normal breast epithelium, ductal carcinoma insitu, microinvasive Carcinoma of the breast and invasive breast cancer. $\mathrm{Br} \mathrm{J}$ Cancer 20II; 105(I): 13-7. [Crossref]

15. Chikman B, Vasyanovich S, Lavy R, Habler L, Tolstov G, Kapiev A, et al. COX2 expression in high-grade breast cancer: evidence for prognostic significance in the subset of triple-negative breast cancer patients. Med Oncol 2014; 3I(6): 989. [Crossref]

16. Schexnayder C, Broussard K, Onuaguluchi D, Poché A, Ismail M, McAtee LF, et al. Metformin Inhibits Migration and Invasion by Suppressing ROS Production and COX2 Expression in MDA-MB Breast Cancer Cells. Int J Mol Sci 2018; 19(II): 3692. [Crossref]

17. Serra KP, Peres RMR, Sarian LO, Vasallo J, Pinto GA, Silva GRdP, et al. Cyclooxygenase-2 (COX2) and p53 protein expression are interdependent in breast cancer but not associated with clinico-pathological surrogate subtypes, tumor aggressiveness and patient survival. Acta Histochemica 2016;II8(2): 176-82. [Crossref]

18. Perez AA, Balabram D, Rocha RM, Silva SÁ, Gobbi H. Co-Expression of pl6, Ki67 and COX-2 is associated with basal phenotype in high-grade ductal carcinoma in situ of the breast. J Histochem Cytochem 2015; 63(6): 408-16. [Crossref]

19. Tury S, Becette $V$, Assayag F, Vacher S, Benoist C, Kamal M, et al Combination of COX2 expression and PIK3CA mutation as prognostic and predictive markers for celecoxib treatment in breast cancer. Oncotarget 2016; 7(5I): 85124-4l. [Crossref]

20. Ristimaki A, Sivula A, Lundin J, Lundin M, Salminen T, Haglund C, et al. Prognostic significance of elevated cyclooxygenase-2 expression in breast cancer. Cancer Res 2002; 62(3): 632-5.

21. Glynn SA, Prueitt RL, Ridnour LA, Boersma BJ, Dorsey TM, Wink DA, et al. COX-2 activation is associated with Akt phosphorylation and poor survival in ER-negative, HER2-positive breast cancer. BMC Cancer 2010; 10: 626. [Crossref]

22. Basudhar D, Bharadwaj G, Somasundaram $V$, Cheng RYS, Ridnour $L A$, Fujita $M$, et al. Understanding the tumour micro-environment communication network from an NOS2/COX2 perspective. $\mathrm{Br} \mathrm{J}$ Pharmacol 2019; 176(2): 155-76. [Crossref]

23. Dhakal HP, Naume B, Synnestvedt M, Borgen E, Kaaresen R, Schlichting $E$, et al. Expression of cyclooxygenase-2 in invasive breast carcinomas and its prognostic impact.Histol. Histopathol 2012; 27(10): |3|5-25. 
24. Herrera ACSA, Panis C, Victorino VJ, Campos FC, Colado-Simao NA, Cechini $A L$, et al. Molecular subtype is determinant on inflammatory status and immunological profile from invasive breast cancer patients. Cancer Immunol Immunother 2012; 6I(II): 2193-20I. [Crossref]

25. Xu F, Li M, Zhang C, Cui J, Liu J, Li J, et al. Clinicopathological and prognostic significance of COX2 immunohistochemical expression in breast cancer: a meta- analysis. Oncotarget 2017; 8: 6003-12. [Crossref]

26. Cheang MCU, Chia SK, Voduc D, Gao D, Leung S, Snider J, et al. Ki67 index, HER2 status and prognosis of patients with Luminal B breast cancer. J Natl Cancer Inst 2009; I0I(I0): 736-50. [Crossref]

27. Brandao RD, Veeck J, Van de Vijver KK, Lindsey P, de Vries B, van Elssen $\mathrm{CH}$, et al. A randomised controlled phase II trial of pre-op- erative celecoxib treatment reveals anti-tumour transcriptional response in primary breast cancer. Breast Cancer Res 2013; I5(2): R29. [Crossref]

28. Martin LA, Davies GL, Weigel MT, Betambeau N, Hills MJ, Salter J, et al. Pre-surgical study of the biological effects of the selective cyclo-oxygenase- 2 inhibitor celecoxib in patients with primary breast cancer. Breast Cancer Res Treat 20I0; 123(3): 829-36. [Crossref]

29. Chang SH, Liu CH, Conway R, Han DK, Nithipatikom K, Trifan OC, et al. Role of prostaglandin E2-dependent angiogenic switch in cyclooxygenase 2-induced breast cancer progression. Proc Natl Acad Sci USA 2004; I0I(2): 59I-6. [Crossref]

30. Zha $S$, Yegnasubramanian $V$, Nelson WG, Isaacs WB, De Marzo AM: Cyclo-oxygenases in cancer: progress and perspective. Cancer Lett 2004; 215(I): I-20. [Crossref] 